\title{
Hormonal contraception and chemoprevention of female cancers
}

\author{
M C Pike and D V Spicer
}

Departments of Preventive Medicine and Medicine, University of Southern California/Norris Comprehensive Cancer Center, 1441 Eastlake Avenue, Los Angeles, California 90033-0800, USA

(Requests for offprints should be addressed to M C Pike)

\begin{abstract}
Oral contraceptive $(\mathrm{OC})$ use significantly reduces the risk of endometrial and ovarian cancer, has only a minimal effect on breast cancer, but may increase the risk of cervical cancer. These effects can be readily explained in terms of the effects of OCs on cell proliferation in these tissues. This analysis suggests how a hormonal contraceptive based on a GnRH agonist plus low-dose add-back sex steroids could be made that would greatly reduce lifetime risk of breast and ovarian cancer. Such a hormonal contraceptive is also likely to significantly reduce the lifetime risk of cervical cancer. It is also likely to reduce the risk of endometrial cancer, although not to the same extent as OCs.
\end{abstract}

Endocrine-Related Cancer (2000) 7 73-83

\section{Introduction}

Hormonal chemoprevention of ovarian cancer was first demonstrated in the late 1970s. The chemopreventive agent was oral contraceptives (OCs; the 'Pill'). The protection achieved was clinically highly significant and dependent on the duration of use: 5 years of OC use provides a long-term reduction in risk of some $32 \%$, and 10 years of use a reduction of some 54\% (Pike \& Spicer 1993). Hormonal chemoprevention of endometrial cancer was first demonstrated in the early 1980s. The chemopreventive agent was again OCs. The protection was again clinically highly significant and dependent on the duration of use: 5 years of OC use provides a long-term reduction in risk of some $46 \%$, and 10 years of use a reduction of some $71 \%$ (Pike \& Spicer 1993). These chemopreventive effects of OCs do not, however, extend to breast cancer, and a significantly increased risk of cervical cancer has been noted in OC users.

The critical direct actions of the natural ovarian hormones, estradiol and progesterone, and their synthetic analogs in OCs, on endometrial, breast and cervical cells are to affect cell division rates. OCs respectively decrease, leave effectively unchanged and appear to increase mitotic activity of endometrial, breast and cervical cells. OCs indirectly reduce the mitotic activity of ovarian epithelial cells. The effects of OCs on cancer rates in these tissues can be largely explained on the basis of these differing effects on cell proliferation.

An obvious way to attempt to extend the protective effects of OCs from endometrial and ovarian cancer to include breast and cervical cancer in addition is to look for ways of simultaneously reducing cell division in all four tissues. The design requirements of a hormonal contraceptive to achieve this are described in Table 1 and are discussed below.

Table 1 Design requirements of a hormonal contraceptive to reduce cancer risk

\begin{tabular}{ll}
\hline Organ & Design aim \\
\hline Endometrium & $\begin{array}{l}\text { Reduce exposure of the endometrium to } \\
\text { 'unopposed' estrogen } \\
\text { Oveduce ovulation frequency and follicle } \\
\text { stimulation }\end{array}$ \\
Breast & $\begin{array}{l}\text { Reduce exposure of the breast to 'estrogen } \\
\text { plus progestin' }\end{array}$ \\
Cervix & $\begin{array}{l}\text { Reduce exposure of the cervix to 'estrogen } \\
\text { plus progestin' }\end{array}$ \\
\hline
\end{tabular}

The contraceptive approach we have proposed is to block ovarian function with a gonadotropin-releasing hormone agonist (GnRHA) and to counteract the induced hypo-estrogenism with a low dose of estrogen and intermittent (12-14 days every 3-4 months) progestin (Pike et al. 1989, Spicer et al. 1993). This approach avoids having to use the high dose of estrogen-progestin of OCs to block ovulation. The main aim of this approach is chemoprevention of breast and ovarian cancer while providing a hormonal contraceptive that will be highly acceptable to most women. This approach has been demonstrated to be highly acceptable to women at high risk of breast cancer (Spicer et al. 1993). There is substantial evidence that this approach will reduce ovarian cancer and almost as much evidence that it will 
reduce breast cancer. Endometrial cancer protection is not achieved to the extent achieved by OCs, as OCs deliver a high daily dose of progestin with each daily dose of synthetic estrogen. The results of a recent epidemiological study, however, suggest that, as long as the duration of the intermittent progestin is at least 13 days and the estrogen dose is low, hyperplasia will not be induced and sloughing of the endometrium will be sufficient to provide significant protection against endometrial cancer (Pike et al. 1997).

A recent epidemiological study found that oophorectomy, even if combined with some add-back hormone replacement therapy, was associated with a sharp reduction in risk of breast cancer in women at high genetic risk of the disease (Rebbeck et al. 1999). These results provide strong support for this GnRHA approach to chemoprevention of breast cancer, and that the approach is equally applicable to high-risk women. These epidemiological observations are also strongly supported by the results of a recently published randomized clinical trial of using a GnRHA for treating premenopausal breast cancer patients; this trial showed a marked reduction in the occurrence of contralateral primaries in the GnRHA-treated patients (Baum 1999).

\section{Endometrial cancer}

The incidence of most non-hormone-dependent cancers rises continuously and increasingly rapidly with age; and a plot of the logarithm of incidence against the logarithm of age produces a straight line as predicted by the multi-stage theory of carcinogenesis and confirmed by modern molecular biology studies (Fig. 1). In contrast, the age-incidence curve of cancer of the endometrium shows a distinct slowing of the rate of rise at the age of menopause (top curve in Fig. 2). The key etiologic elements are therefore present in premenopausal women, but are reduced following menopause. Increasing parity also decreases endometrial cancer risk. Obesity in both pre- and postmenopausal women, and estrogen replacement therapy in postmenopausal women, significantly increases endometrial cancer risk. OC use significantly decreases endometrial cancer risk (Centers for Disease Control 1983b, 1987b, Henderson et al. 1983, Key \& Pike 1988a).

These risk factors are all explained by the mitogenic action of estrogen in the absence of progestin (so called 'unopposed estrogen') in stimulating endometrial-cell division. During a normal menstrual cycle, endometrial-cell mitotic activity peaks during the early follicular phase, when serum estradiol levels are approximately $50 \mathrm{pg} / \mathrm{ml}$; further increases in unopposed estradiol concentration do not appear to increase the mitotic rate (Fig. $3 a$ and $b$ ). Following ovulation, serum progesterone rises and endometrial-cell proliferation ceases despite continued estradiol levels in excess of $50 \mathrm{pg} / \mathrm{ml}$. At low serum estradiol concentrations (5 $\mathrm{pg} / \mathrm{ml})$, as occur in slender postmenopausal women, endometrial-cell mitotic activity is very low. There is thus a

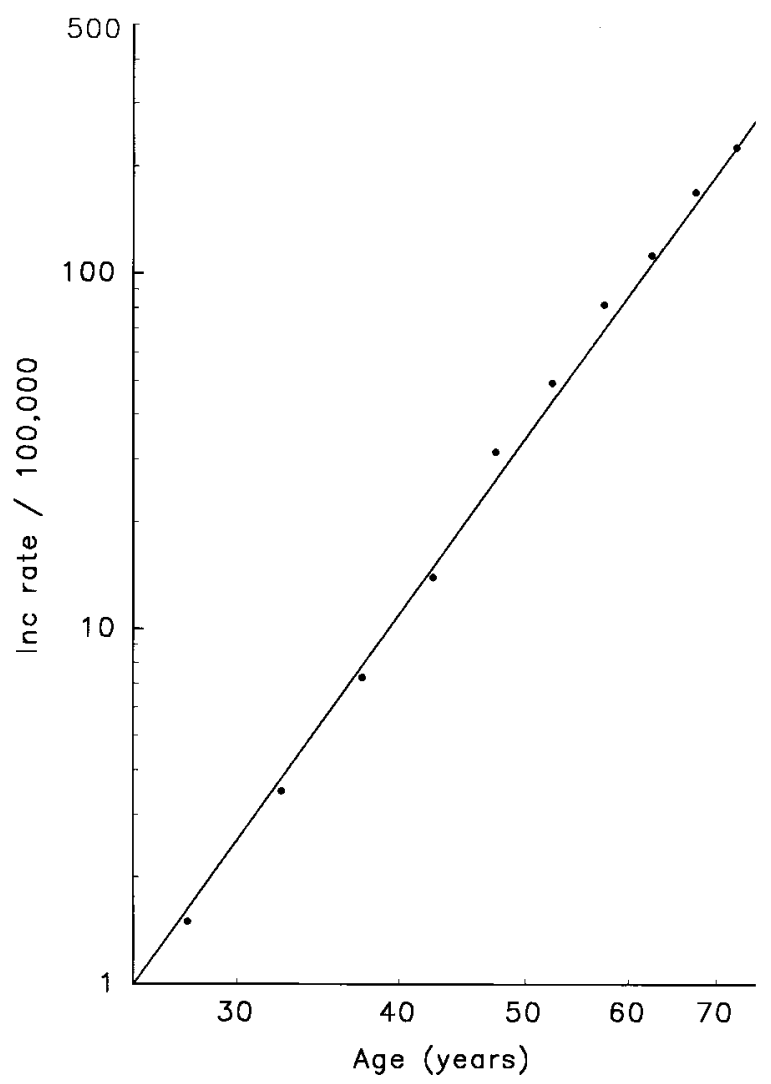

Figure 1 Age-specific incidence (Inc) rates for colorectal cancer in US white females 1969-1971 (Cutler \& Young 1975).

dose-response relationship between unopposed estradiol concentration and endometrial mitotic rate in the range from around 5 to around $50 \mathrm{pg} / \mathrm{ml}$.

Early menopause reduces endometrial cancer risk by reducing the serum unopposed-estrogen concentration to a very low level. Progesterone effectively opposes estrogen throughout pregnancy, so increasing parity is associated with decreasing risk. In premenopausal women, obesity increases risk through the increased anovulation of such women, and their serum estradiol level is sufficiently high to cause maximal endometrial-cell proliferation. In obese postmenopausal women, unopposed-serum estrogen is increased and sex-hormone-binding globulin is decreased, so that there is an increase in bioavailable estrogen. Estrogen replacement therapy increases serum unopposed estrogen.

OCs contain an estrogen and a high-dose progestin; endometrial cells are, thus, exposed to unopposed estrogen only during the 7 days in 28 during which the $\mathrm{OC}$ is not taken, and the endogenous estrogen level during these 7 days remains quite low. Meta-analysis of the population-based epidemiological studies shows a reduction in endometrial cancer risk of around $11.7 \%$ per year of OC use (Pike \& 


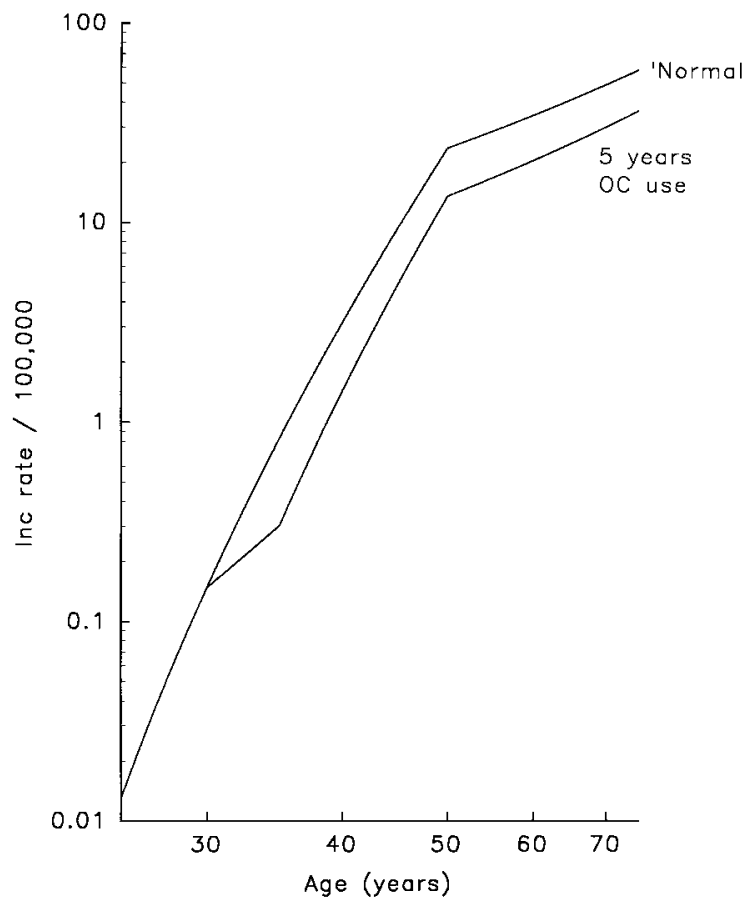

Figure 2 Age-specific incidence (Inc) rates for endometrial cancer in women in the Birmingham region of the UK 19681972 (Waterhouse et al. 1976). Note: this curve is derived from UK data because US data are severely biased owing to the high oophorectomy rate in the USA. The lower curve is for such women using OCs for 5 years from age 30 to age 35 .

Spicer 1993), i.e. a $46 \%$ reduction per 5 years of OC use. The lower curve in Fig. 2 translates these results to the age-incidence curve of endometrial cancer; the curve shows the effect of 5 years of OC use from age 30 to age 35. The slope of the curve is much reduced during the time OCs are used and then increases again once OC use is stopped, but the protection gained continues after stopping.

\section{Ovarian cancer}

The age-incidence curve of cancer of the ovary, like the age-incidence curve for cancer of the endometrium, shows a distinct slowing of the rate of rise at the age of menopause (top curve in Fig. 4). Again the key etiologic elements are present in premenopausal women, but are reduced following menopause. The other major factor determining ovarian cancer risk is parity; increasing parity decreases risk, and increasing duration of breast feeding also decreases risk. OC use significantly decreases ovarian cancer risk (Casagrande et al. 1979, Willett et al. 1981, Centers for Disease Control 1983a, 1987a, Risch et al. 1983). These protective factors interrupt ovulation and reduce intra-ovarian hormone levels, in particular, intra-ovarian estrogen levels. (a)

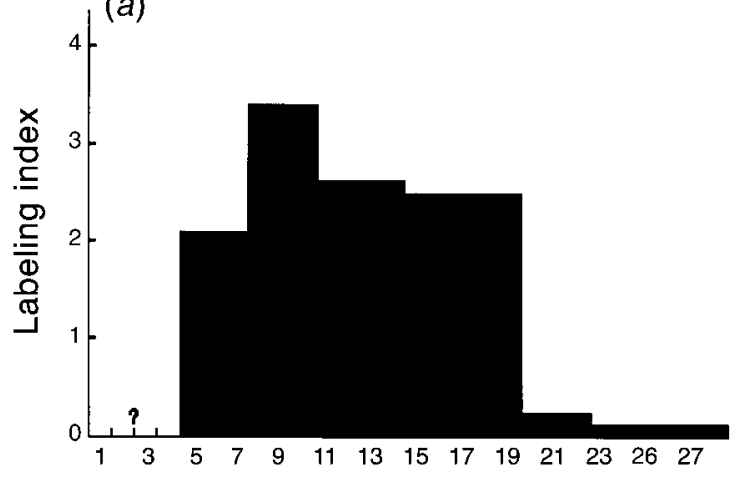

(b)

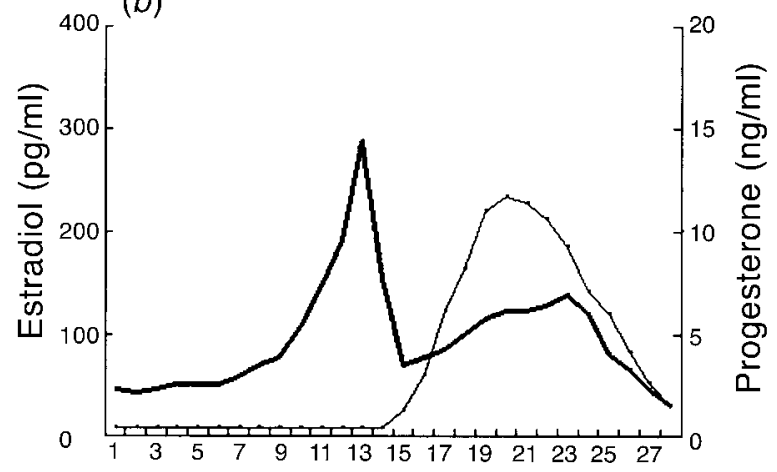

(c)

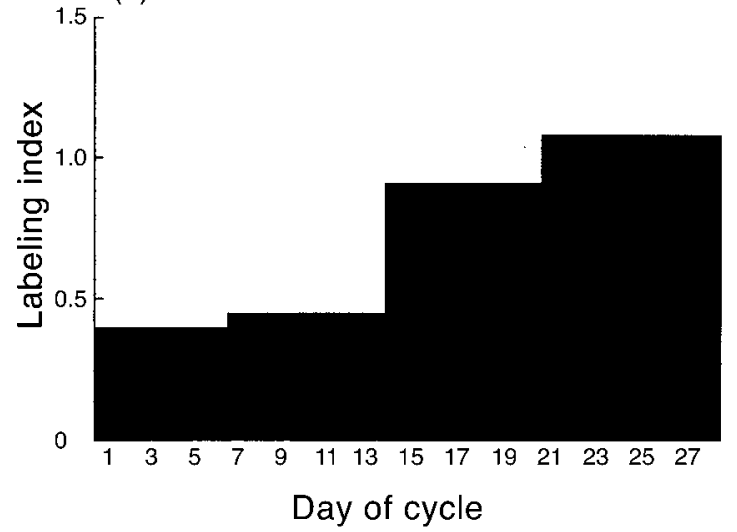

Figure 3 (a) Endometrial-cell labeling index (mitotic rate) by day of cycle (day 1 is the first day of menses and a 28-day cycle is assumed with ovulation on day 14) (Ferenczy et al. 1979). (b) Serum concentrations of estradiol (heavier line) and progesterone (lighter line) by day of cycle (Goebelsmann \& Mishell 1979). (c) Breast-cell labeling index (mitotic rate) by day of cycle in parous women (Anderson et al. 1989). 


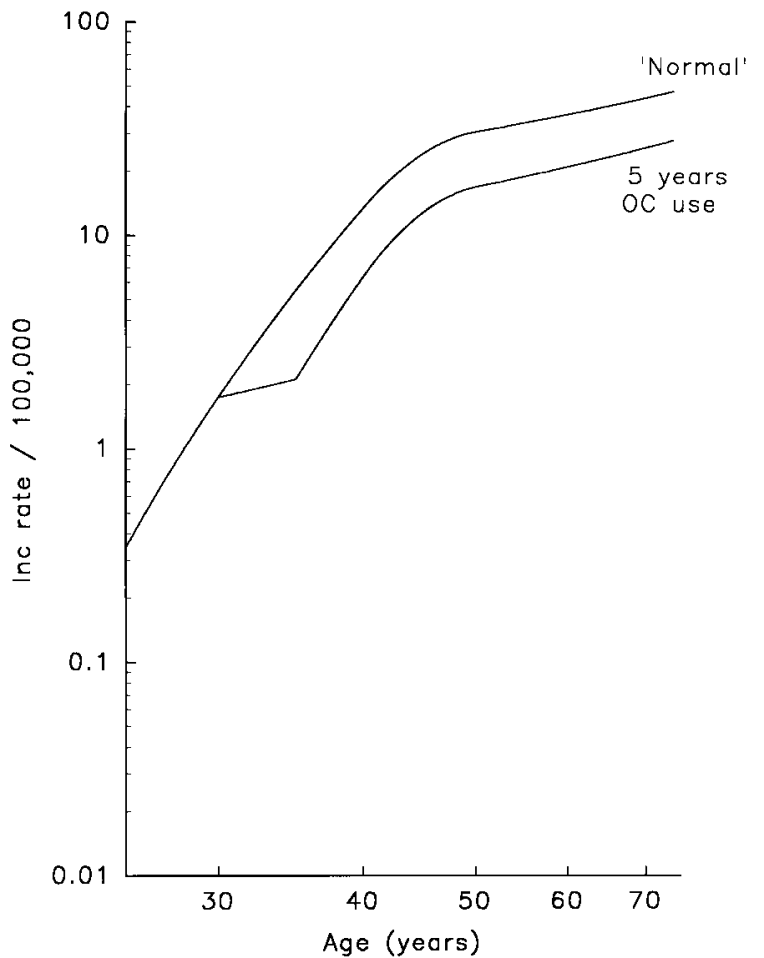

Figure 4 Age-specific incidence (Inc) rates for ovarian cancer in women in the Birmingham region of the UK 19681972 (Waterhouse et al. 1976). Note: this curve is derived from UK data because US data are severely biased owing to the high oophorectomy rate in the USA. The lower curve is for such women using OCs for 5 years from age 30 to age 35.

The incessant ovulation hypothesis for ovarian cancer proposes that ovarian cancer risk is essentially determined by the increased proliferative activity of the ovarian surface epithelium required to accomplish repair of the surface after each ovulation (Fathalla 1971, 1972). The incessant ovulation hypothesis provides a quantitative explanation of the decreasing risk found with pregnancies, breast feeding and OC use (Pike 1987), but cannot explain the much reduced incidence rates of ovarian cancer found until quite recently in low-risk Asian countries. Until quite recently the age-specific incidence rates of ovarian cancer were very much lower in China and Japan than in the USA. For example, in 1970, before the widespread use of oral contraceptives began to cause a significant fall in the incidence of ovarian cancer in young women in the USA, the ovarian cancer incidence rate (per 100000 females) at ages 45-54 was 30.8 in the USA, compared with 6.4 in Japan. This 4.8-fold difference cannot be explained on a simple incessant ovulation hypothesis. Japanese women born around 1920 had menarche some 1.7 years later than US white women born around that time, they had 0.5 more live births, and their average menstrual cycle may have been as much as 2 days longer (Grove et al. 1968, Hoel et al. 1983, Japan Statistical Yearbook 1998). These differences can only account for a 1.7-fold lower rate in the Japanese on the incessant ovulation hypothesis (Pike 1987). The observed difference in rates can, however, be readily accounted for on a hypothesis that includes intra-ovarian estradiol levels as a risk factor. Estradiol at an intra-ovarian concentration is a potent mitogen to ovarian cystadenoma cells (MP Luo, MC Pike, W Zheng, MR Stallcup \& L Dubeau, unpublished observations) and women in low-risk Asian countries have serum estradiol levels some $25 \%$ lower than those of US women (Goldin et al. 1986, Bernstein et al. 1990, Key et al. 1990). Such a reduction is quite sufficient to account for the remaining difference in ovarian cancer rates between Japan and the USA (Pike 1987).

OC use blocks ovulation and markedly reduces intra-ovarian estrogen levels. Meta-analysis of populationbased epidemiological studies shows a reduction in ovarian cancer risk of approximately $7.5 \%$ per year of OC use (Pike \& Spicer 1993), i.e. a $32 \%$ reduction per 5 years of OC use. The lower curve in Fig. 4 translates these results to the age-incidence curve of ovarian cancer; the curve shows the effect of 5 years of OC use from age 30 to age 35 . The slope of the curve is much reduced during the time OCs are used and then increases again once OC use is stopped, but the protection gained is only slightly reduced after stopping and again the protective effect should be lifelong (as it is for parity).

$\mathrm{OC}$ use has been found to be equally protective against hereditary (mutBRCA1/2) ovarian cancer (Narod et al. 1998).

\section{Breast cancer}

The age-incidence curve of cancer of the breast, like cancer of the endometrium and ovary, shows a distinct slowing of the rate of rise at the age of menopause (Fig. 5). Again the key etiologic elements are present in premenopausal women, but are reduced following menopause. Breast cancer risk decreases with increasing age at menarche, and obesity during the postmenopausal years increases breast cancer risk, but obesity during the premenopausal years actually reduces risk (Key \& Pike 1988b). Use of menopausal estrogen replacement therapy only marginally increases breast cancer risk, but use of estrogen plus progestin therapy in the postmenopausal period increases breast cancer risk substantially (Magnusson et al. 1999, Ross et al. 2000, Schairer et al. 2000).

During the menstrual cycle, breast-cell proliferation is lowest during the follicular phase and then increases some twofold in the luteal phase (Fig. 3c; Pike et al. 1993). This suggests that estradiol induces cell division and that the combined effect of estradiol and progesterone together is considerably greater - the estrogen plus progestin hypothesis. 


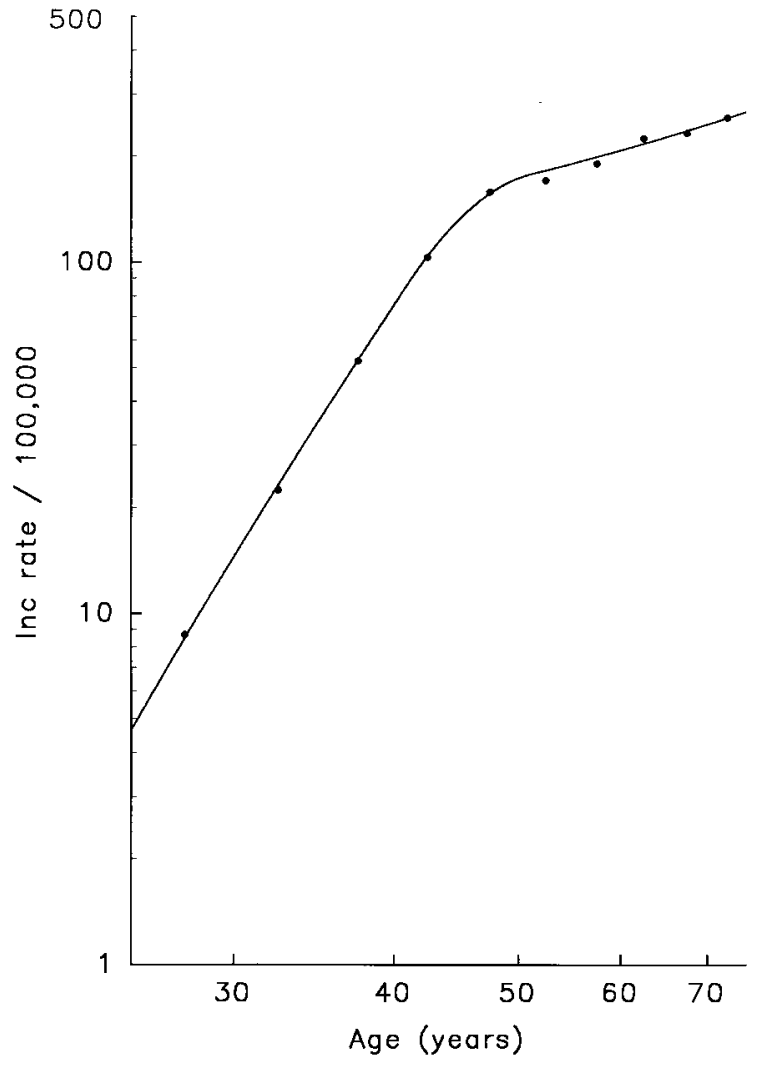

Figure 5 Age-specific incidence (Inc) rates for breast cancer in US white females 1969-1971 (Cutler \& Young 1975).

In the postmenopausal period, when estradiol levels are low, and progesterone is absent, breast-cell proliferation is very low. The protective effects of late menarche and early menopause are thus readily explained by this hypothesis. The contradictory effects of obesity are also predicted by this hypothesis. The increased anovulation associated with premenopausal obesity will decrease breast exposure to both estradiol and progesterone; after menopause, the decreased risk associated with premenopausal obesity is gradually eliminated and an increased risk finally achieved by the increased bioavailable estrogen levels associated with postmenopausal obesity. The reason that risk is only slightly increased by estrogen replacement therapy is the relative low dose of estrogen used in estrogen replacement therapy (Key \& Pike 1988b) and the absence of a progestin. The addition of a relatively high-dose progestin to estrogen replacement therapy is predicted to increase the risk substantially. This is precisely what is observed; the three recent large-scale population-based epidemiological studies (Magnusson et al. 1999, Ross et al. 2000, Schairer et al. 2000) suggest that the added risk is increased from about $10 \%$ per 5 years of use with estrogen replacement therapy to approximately $30 \%$ per 5 years of estrogen plus progestin replacement therapy. These results are strongly supported by the findings of greatly increased breast-cell proliferation in postmenopausal women on estrogen plus progestin replacement therapy (Hofseth et al. 1999), and the findings in a randomized trial of greatly increased mammographic densities with such use of estrogen plus progestin (Greendale et al. 1999).

Studies of OC use and breast cancer have found either no effect or a slight increase in risk. This is entirely consistent with the estrogen plus progestin hypothesis. OCs contain an estrogen and a progestin. OCs inhibit gonadotropin secretion, thus reducing ovarian steroidogenesis to very low levels, but the ovarian steroid loss is compensated for by the synthetic estrogen and progestin of the OC. One would predict that breast-cell proliferation in women taking OCs would be less than, equal to, or greater than that observed during a normal menstrual cycle, depending on the dose of estrogen and progestin in the particular OC. Direct observational studies of breast-cell proliferation in women taking OCs suggest that the total breast cell proliferation is very similar over an OC cycle and a normal menstrual cycle (Anderson et al. 1989, Williams et al. 1991). These results predict that breast cancer risk should not be substantially affected by OC use, as is observed.

\section{Cervical cancer}

The incidence of invasive cervical cancer fluctuates widely in different (birth) cohorts of women. It is also markedly reduced by cervical cancer screening. To note the true age-incidence distribution of the disease it is necessary to use cohort-specific data for time-periods before cervical cancer screening (Pap screening) was common. Such an analysis was conducted by Cook \& Draper (1984) for cervical cancer mortality. Figure 6 shows the age-specific mortality curve that can be derived from their results. Inspection of some age-incidence data from the same time-periods as studied by these authors show that this curve reasonably accurately reflects the related age-incidence curve of invasive cancer with a lag period of a few years. Figure 6 strongly suggests that hormones may also play an important role in the development of cervical cancer.

Konishi et al. (1991) found that the mitotic rate of cervical cells fluctuated during the menstrual cycle in a manner similar to that of breast cells; the cervical mitotic rate was 1.8-fold greater in the luteal phase that in the follicular phase and was much reduced in postmenopausal women. The mitotic rate during pregnancy was as high as in the luteal phase of the menstrual cycle. One would therefore predict that menopause would protect against cervical cancer (as is suggested by Fig. 6), that pregnancies would increase risk (there is considerable evidence of this), and that, since OCs contain both an estrogen and a progestin, the effect of 


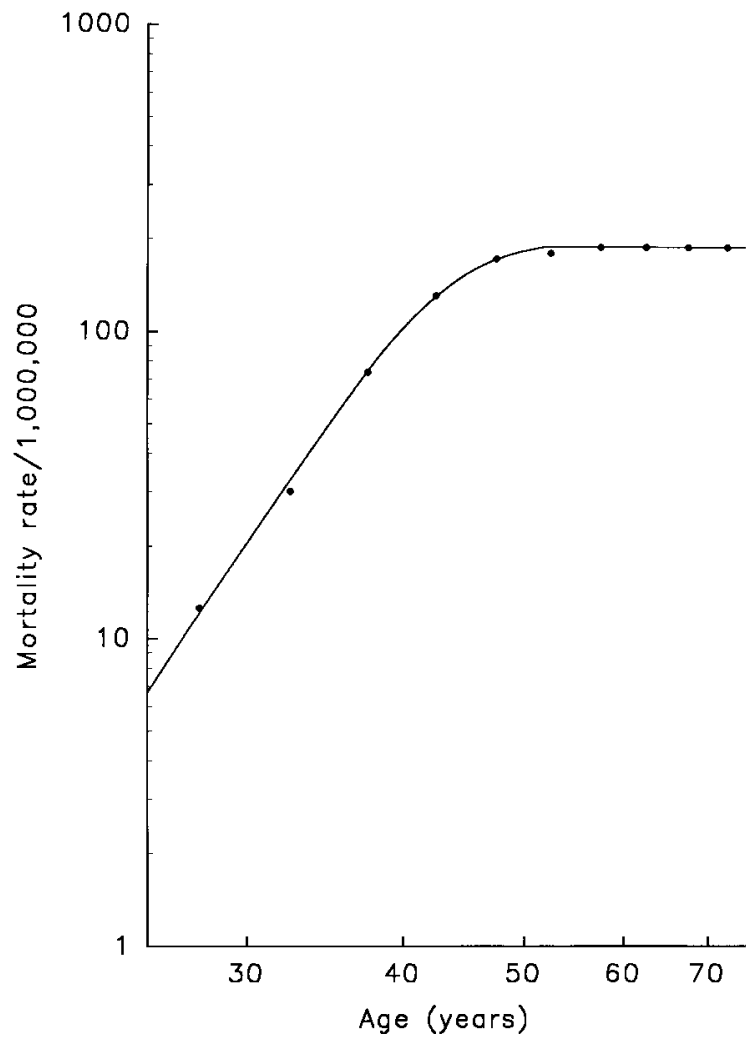

Figure 6 Age-specific cohort mortality rates for cervical cancer in UK females (Cook \& Draper 1984).

the OCs would depend on the estrogen-progestin dose, much as it does for breast cancer.

OC use and cervical cancer is unusually difficult to study epidemiologically because there is a positive association of OC use with the frequency of Pap screening, and in any particular community there may be a positive association between $\mathrm{OC}$ use and the very significant sexual risk factors for cervical cancer.

The positive association of OC use with the frequency of Pap screening inevitably produces a positive association of carcinoma in situ (CIS) of the cervix with OC use whether or not there is a true association, i.e. an association independent of Pap screening history. Studies of OC use and cervical CIS must therefore adjust for Pap screening history; and, in particular, positive studies which do not do this are not interpretable. In contrast, the positive association of $\mathrm{OC}$ use with the frequency of Pap screening will downwardly bias any association of OC use with invasive cervical cancer, since the natural history of such cancers will be affected by Pap screening, i.e. they will tend to be picked up by screening at a premalignant stage and so never reach an invasive stage. Studies of OC use and invasive cervical cancer must therefore also adjust for Pap screening history; and, in particular, negative studies which do not do this are not interpretable.

A positive association of OC use with sexual history risk factors for cervical cancer will inevitably produce a positive bias in the observed associations of OC use with both cervical CIS and invasive cervical cancer. Studies of OC use and cervical CIS and invasive cervical cancer must therefore adjust for sexual history; and, in particular, positive studies which do not do this are not interpretable.

There are three population-based studies of OC use and invasive cervical cancer in which adjustment was made for history of Pap screening and sexual history (Brinton et al. 1986, Peters et al. 1986, Irwin et al. 1988). All three studies found evidence of an increased cervical cancer risk in OC users, although only the study of Brinton et al. (1986) had a substantial amount of data on OC use, and only the results of this study were statistically significant. A meta-analysis of the three studies showed an increase in invasive cervical cancer risk of 3.6\% per year of OC use (Pike \& Spicer 1993).

There is a clear need for further studies of the relationship of hormones to cervical cancer risk.

\section{Cancer prevention by design}

Table 1 summarized the design requirements of a hormonal contraceptive to reduce the risks of endometrial, ovarian, breast and cervical cancer based on the above analysis of the hormonal etiology of these cancers. OCs fulfill the design requirements for the prevention of endometrial and ovarian cancer. OCs do not provide protection against breast or cervical cancer, because OCs deliver estrogen plus progestin to the breast and cervix in quantities sufficient to replace the action of the natural estrogen plus progesterone of the normal menstrual cycle. The dose of sex steroids in present-day OCs is close to the lowest dose possible while still maintaining their contraceptive effect of preventing ovulation.

OCs are designed to achieve two separate goals. The first is to prevent ovulation, and the second is to counteract the effects of the hypo-estrogenemia caused by the blocking of ovarian function associated with the first goal. The progestin component of OCs has a vital role in suppressing ovulation, but it only has a minor role (this with respect to bone metabolism) in dealing with the associated hypoestrogenemia. The lowest estrogen dose in conventional OCs is $30 \mu \mathrm{g}$ ethinyl-estradiol. If the first goal of OCs, i.e. preventing ovulation, could be achieved by some other means, could the hypo-estrogenemia be countered with a lower dose of estrogen? This issue can be addressed by considering the dose of estrogen required to control menopausal hypo-estrogenemia, in particular hot flushes and adverse changes in serum cholesterol and calcium balance. The dose of ethinyl-estradiol required as estrogen replacement therapy has not been studied intensively, but the studies that are available suggest that the required dose is in 
the 5-15 $\mu \mathrm{g}$ range (Spicer et al. 1991), i.e. at most half the dose used in current low-dose OCs.

GnRHAs, when given chronically, inhibit pituitary release of follicle-stimulating hormone and luteinizing hormone, reversibly inhibit ovulation and reduce ovarian sex-steroid production to postmenopausal levels. Thus the reversible ovulation-inhibiting function of OCs can be achieved by using a GnRHA. This enables concentration to be addressed solely on finding the combination of add-back sex steroids of greatest benefit to the user's health. As noted above, a daily dose of approximately $10 \mu \mathrm{g}$ ethinyl-estradiol appears likely to be all the estrogen needed. Such a GnRHA plus low-dose estrogen contraceptive will achieve the design requirements for hormonal chemoprevention of ovarian, breast and cervical cancer. However, such a regimen will not prevent endometrial cancer, and some progestin is needed to control any endometrial hyperplasia which may be caused by the unopposed estrogen. Some recent studies of the effects of estrogen plus progestin replacement therapy on endometrial cancer risk suggest that prevention of endometrial cancer can be achieved by adding progestins for 13 days every third or fourth 28-day cycle of the GnRHA plus low-dose add-back estrogen regimen (see below). This amount of progestin should not affect the protective effect of the regimen against ovarian cancer as there is no evidence that progestins increase epithelial-cell division in the ovary. The predicted protection against ovarian cancer using the prototype contraceptive should be at least as great as is observed with OCs; i.e. a $32 \%$ lifelong reduction if used for 5 years, and a $69 \%$ reduction if used for 15 years. Greater reductions (41\% and $84 \%$ ) are likely (Pike et al. 1989). Any progestin is predicted to somewhat reduce the protective effects against breast and cervical cancer (but see below). We estimated that such an intermittent progestin regimen will reduce lifelong breast cancer risk by $31 \%$ if used for 5 years, $53 \%$ if used for 10 years, and $70 \%$ if used for 15 years (Spicer et al. 1991). The effect on cervical cancer risk is difficult to predict, but the reduced steroid dose, in particular the reduced progestin dose, is likely to produce less proliferative stimulation of the cervix than normal ovulatory cycles and hence a reduction of cervical cancer risk.

\section{Required progestin}

Unopposed estrogen replacement therapy (at the doses usually prescribed in the USA) produces significant endometrial-cell proliferation (King \& Whitehead 1984). The progestin medroxyprogesterone acetate (MPA) at $5 \mathrm{mg} /$ day reduces such cell proliferation to effectively zero within 6 days despite continued estrogen (Lane et al. 1986). However, such short-duration progestin use does not completely remove the risk of hyperplasia. Paterson et al. (1980) found with conjugated estrogen at $1.25 \mathrm{mg} /$ day, given for 21 days per 28-day cycle, that the incidence of hyperplasia was 21.0 (per 1000 woman-months) when no progestin was used. The incidence declined to 4.0 when a progestin was used for the last 5-7 days and to 1.3 when used for the last 10 days. The incidence of hyperplasia was zero when the progestin was used for 13 days. The latter is also the number of days recommended by King \& Whitehead (1984).

If endometrial cell proliferation in the basalis (stem-cell) layer was the key to increased endometrial cancer risk from estrogen replacement therapy, then there would still be a substantial increased risk even with 13 days of progestin, since there would still be unopposed estrogen for 12-15 days per treatment cycle. However, in our large epidemiological case-control study of endometrial cancer, we found only a small reduction of the estrogen replacement therapy-induced risk from 7 days of progestin, but a complete abolition of the increased risk with 10 or more days of progestin (Pike et al. 1997). A simple cell-proliferation model for endometrial cancer is clearly untenable.

Flowers et al. (1983) found 7 days of progestin did 'not cause all the endometrium to desquamate to the basalis layer ... (only) 40 to $50 \%$ of the functional layer . . . was lost'. If these functionalis cells are susceptible to cancer, and a greater proportion of such cells are lost with longer progestin therapy, this would provide an explanation for the sharp distinction between 7 and 10 days of progestin. This would also be completely in line with the virtual complete abolition of hyperplasia with a 10-day progestin regimen (Paterson et al. 1980). It would also be consistent with the observation of pathologists that early stage tumors often appear to have arisen in the functionalis. If the extent of endometrial shedding in a normal menstrual cycle was no more than after a 7-day course of progestin, this would explain the sharp rise with age of endometrial cancer rates in premenopausal women even in countries where obesity is uncommon, so that obesity-related anovulation is not an explanation. There do not appear to be any data addressing this possibility.

Progestins need to be delivered to the endometrium in a manner that will be associated with low serum progestin levels so as to have a minimal effect on the breast. A vaginal (Miles et al. 1994, Fanchin et al. 1997) or direct endometrial (Shoupe et al. 1991) route of administration is optimal in this sense. The vaginal route provides a high endometrial progestin level with very low serum levels. The direct endometrial route of administration with an intra-uterine device has even lower serum progestin levels. If these routes of administration are unacceptable to a woman, then giving progestins for 13 days every 3-4 months may provide satisfactory protection of the endometrium with proportionally less effect on the breast than monthly administration. Two clinical trials of administering $10 \mathrm{mg}$ MPA/day for 14 days every 3 months have been published in which the dose of conjugated estrogen was $0.625 \mathrm{mg} /$ day (Ettinger et al. 1994, Williams et al. 1994). Both studies suggest that this approach may be satisfactory with such 
low-dose estrogen. In a small 2-year study we had good results with administration of MPA every fourth month. The above discussion on the shedding of the functionalis may be the explanation for these good results which could also be predicted from the earlier work of Schiff et al. (1982). More studies of these approaches are urgently needed.

The above discussion is based on the use of a low-dose estrogen regimen $(0.625 \mathrm{mg} /$ day conjugated estrogen as is most commonly prescribed in the USA; Pike et al. 1997). When a $2 \mathrm{mg} /$ day estradiol valerate dose of estrogen was used, every 3-month administration of progestin did not control hyperplasia (Cerin et al. 1996) nor was monthly cyclical progestin sufficient to completely obviate any increased endometrial cancer risk (Weiderpass et al. 1999). We would hypothesize that this was a higher endometrial estrogen-dose effect but have seen no data on this. Studies to elucidate these contradictory findings are urgently needed.

\section{Some results suggesting validity of predictions}

Rebbeck et al. (1999) studied 'a cohort of women with ... BRCA1 mutations, ... . who underwent bilateral prophylactic oophorectomy but had no history of breast or ovarian cancer and had not had a prophylactic mastectomy'. Control subjects were as above but had not undergone oophorectomy. The oophorectomized women had a $47 \%$ overall reduction in breast cancer risk and a $67 \%$ reduction in incidence 5 or more years after surgery. This reduction was restricted to women whose surgery was before age 50, suggesting that the reduced breast cancer risk was a direct result of the reduced ovarian steroid levels. Hormone replacement therapy 'did not negate (this) finding .... This result lends strong support to our predictions that blocking ovarian function with a GnRHA, even if low-dose add-back sex steroids are used, will significantly reduce breast cancer risk. The reductions in risk observed in this study are even greater than predicted above and very close to that seen with tamoxifen.

Our presumption that GnRHA use is equivalent to oophorectomy is strongly supported by the results of the ZIPP randomized trial (Baum 1999). In this trial the GnRHA, depot Zoladex, was given to premenopausal breast cancer patients, and a $40 \%$ reduction in contralateral disease was observed (Baum 1999).

We carried out a small randomized trial of such a GnRHA, depot Lupron, plus add-back estrogen plus progestin (GEP) regimen in women at high risk of breast cancer (Spicer et al. 1994). The regimen we used is shown in Table 2.

Mammographic densities of women on the contraceptive regimen were quite dramatically decreased after 1 year on the regimen (Fig. 7) (Spicer et al. 1994). This is precisely what happens at menopause and, as we have noted, early menopause is associated with a much reduced risk of breast
Table 2 Pilot GEP contraceptive regimen

\begin{tabular}{|c|c|}
\hline $\begin{array}{l}\text { Agent and } \\
\text { administration }\end{array}$ & Rationale \\
\hline \multicolumn{2}{|l|}{$\mathrm{GnRHA}$} \\
\hline $\begin{array}{l}\text { Leuprolide acetate } \\
\text { depot (Lupron Depot) }\end{array}$ & $\begin{array}{l}\text { Prevent ovulation, and ovarian } \\
\text { sex-steriod production }\end{array}$ \\
\hline \multicolumn{2}{|l|}{ Estrogen } \\
\hline Conjugated estrogens & Prevent bone mineral loss \\
\hline (0.626 mg/day p.o.; & Prevent possible rise in \\
\hline Premarin) 6 days out of & cardiovascular disease risk \\
\hline 7 & Prevent menopausal symptoms \\
\hline & Prevent urogenital atrophy \\
\hline \multicolumn{2}{|l|}{ Progestogen } \\
\hline MPA (10 mg/day p.o.; & Prevent endometrial hyperplasia \\
\hline $\begin{array}{l}\text { Provera) } 13 \text { days every } \\
\text { fourth } 28 \text {-day cycle }\end{array}$ & \\
\hline
\end{tabular}

cancer. The statistically highly significant reductions in mammographic densities at 1 year suggest that the aim of the regimen to reduce breast cancer risk has been accomplished. In an editorial accompanying the report, Feig (1994) suggested this regimen could also lead to a greatly improved efficacy of screening mammography in young women.

Menopause is associated with reduced breast-cell mitotic activity, and we believe that the associated decreased mammographic densities reflect this. The relative amounts of fibrous and adipose tissue are what determine the appearance of the mammographic image. Increased fibrous tissue equates to increased mammographic densities. Since estrogen and progesterone receptors in the breast appear to exist only in epithelial cells, the reduced sex-steroid levels of postmenopausal women are likely to affect fibrous tissue secondarily to their effect on epithelial cells.

Women on the regimen had significantly fewer 'symptoms'. This was mainly due to the sharp reduction of the symptoms associated with premenstrual syndrome (Spicer et al. 1993). Unscheduled bleeding or spotting was infrequent and decreased with time on the regimen. However, despite the use of an estrogen dose which is known to prevent loss of bone mineral density (BMD) in normally postmenopausal women, a small (2-3\%) loss of spinal and femoral BMD was seen in the women on the GEP regimen at 1 year. The reason for this loss of BMD appears to be inhibition of ovarian androgen production. Women on treatment had a $62 \%$ drop in non-sex-hormone-binding globulin-bound testosterone. In contrast, during the early natural postmenopausal period testosterone levels are stable. This provides an explanation of why the estrogen dose we used has been found adequate for preventing bone loss in naturally menopausal women, but not in our volunteers. The addition of non-oral testosterone to the regimen simply to replace that lost by the action of the GnRHA should eliminate this problem, and is currently undergoing clinical trial. 

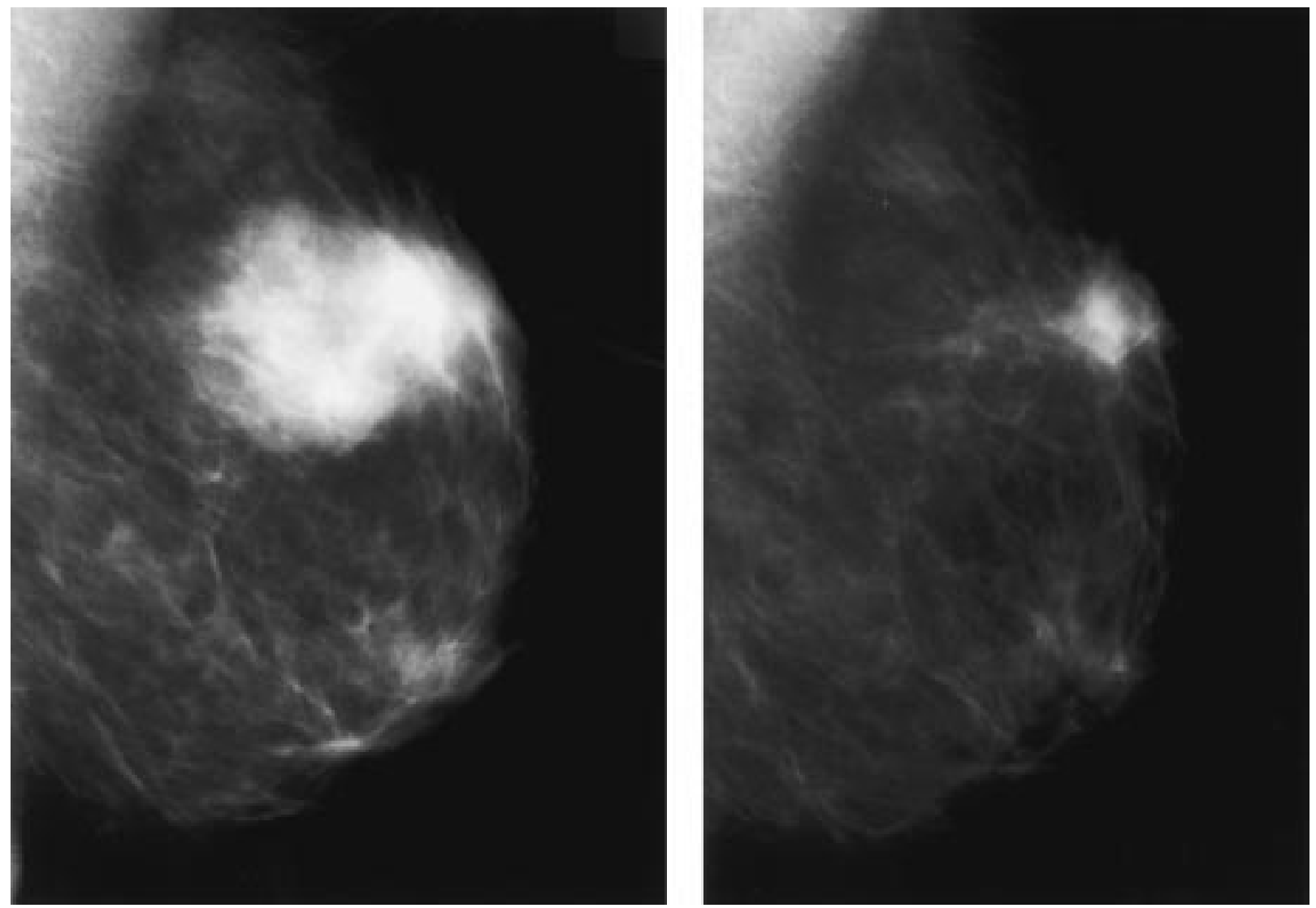

Figure 7 Mammogram at baseline and of the same breast after 1 year of use of the GEP regimen (Spicer et al. 1994).

\section{Declaration of interest}

The authors are associated with Balance Pharmaceuticals, Inc.; a company set up to develop the GnRHA plus the low-dose add-back regimen discussed here.

\section{References}

Anderson TJ, Battersby S, King RJB, McPherson K \& Going JJ 1989 Oral contraceptive use influences resting breast proliferation. Human Pathology 20 1139-1144.

Baum M 1999 Adjuvant treatment of premenopausal breast cancer with zoladex and tamoxifen: results from the ZIPP trial organized by the Cancer Research Campaign (CRC) Breast Cancer Trials Group. Breast Cancer Research and Treatment 57 30 (Abstract).

Bernstein L, Yuan JM, Ross RK, Pike MC, Lobo RA, Stanczyk F, Gao YT \& Henderson BE 1990 Serum hormone levels in premenopausal Chinese women in Shanghai and white women in Los Angeles. Cancer Causes and Control 1 51-58.

Brinton LA, Huggins GR, Lehman HF, Mallin K, Savitz DA, Trapido E, Rosenthal J \& Hoover R 1986 Long-term use of oral contraceptives and risk of invasive cervical cancer. International Journal of Cancer 38 339-344.
Casagrande JT, Louie EW, Pike MC, Ross RK, Louie EW, Roy S \& Henderson BE 1979 'Incessant ovulation' and ovarian cancer. Lancet ii 170-173.

Centers for Disease Control 1983a Oral contraceptive use and the risk of ovarian cancer. Journal of the American Medical Association 249 1596-1599.

Centers for Disease Control 1983b Oral contraceptive use and the risk of endometrial cancer. Journal of the American Medical Association 249 1600-1604.

Centers for Disease Control 1987a The reduction in risk of ovarian cancer associated with oral contraceptive use. New England Journal of Medicine 316 650-655.

Centers for Disease Control 1987b Combination oral contraceptive use and the risk of endometrial cancer. Journal of the American Medical Association 257 796-800.

Cerin A, Heldaas K \& Moeller B 1996 Adverse endometrial effects of long-cycle estrogen and progestogen replacement therapy. New England Journal of Medicine 334 668-669.

Cook GA \& Draper GJ 1984 Trends in cervical cancer and carcinoma in situ in Great Britain. British Journal of Cancer 50 367-375.

Cutler SJ \& Young JL 1975 Third National Cancer Survey: Incidence Data. National Cancer Institute Monograph 41. Ettinger B, Selby J, Citron JT, Vangessel A, Ettinger VM \& Hendrickson MR 1994 Cyclic hormone replacement therapy 
using quarterly progestin. Obstetrics and Gynecology $\mathbf{8 3} 693$ 700.

Fanchin R, de Ziegler D, Bergeron C, Righini C, Torrisi C \& Frydman R 1997 Transvaginal administration of progesterone. Obstetrics and Gynecology 90 396-401.

Fathalla MF 1971 Incessant ovulation - a factor in ovarian neoplasia? Lancet ii 163.

Fathalla MF 1972 Factors in the causation and incidence of ovarian cancer. Obstetrical and Gynecological Survey 27 751-758.

Feig SA 1994 Hormonal reduction of mammographic densities: potential effects on breast cancer risk and performance of diagnostic and screening mammography. Journal of the National Cancer Institute 86 408-409.

Ferenczy A, Bertrand G \& Gelfand MM 1979 Proliferation kinetics of human endometrium during the normal menstrual cycle. American Journal of Obstetrics and Gynecology 133 859-867.

Flowers CE, Wilborn WH \& Hyde BM 1983 Mechanisms of uterine bleeding postmenopausal patients receiving estrogen alone or with a progestin. Obstetrics and Gynecology 61 135143.

Goebelsmann U \& Mishell DR 1979 The menstrual cycle. In Reproductive Endocrinology, Infertility and Contraception, pp 67-89. Eds DR Mishell \& V Davajan. Philadelphia: FA Davis Company.

Goldin BR, Adlercreutz H, Gorbach SL, Woods MN, Dwyer JT, Conlon T, Bohn E \& Gershoff SN 1986 The relationship between estrogen levels and diets of Caucasian American and Oriental immigrant women. American Journal of Clinical Nutrition 44 945-953.

Greendale GA, Reboussin BA, Sie A, Singh HR, Olson LK, Gatewood O, Bassett LW, Wasilauskas C, Bush T \& Barrett-Connor E 1999 Effects of estrogen and estrogenprogestin on mammographic parenchymal density. Annals of Internal Medicine 130 262-269.

Grove RD, Hetzel AM \& National Center for Health Statistics (US) 1968 Vital Statistics Rates in the United States 1940-1960, Table 17.1-ix, 881. US National Center for Health Statistics; Superintendent of Documents, US Government Printing Office, Washington DC.

Henderson BE, Casagrande JT, Pike MC, Mack TM, Rosario I \& Duke A 1983 The epidemiology of endometrial cancer in young women. British Journal of Cancer 47 749-756.

Hoel DG, Wakabayashi T \& Pike MC 1983 Secular trends in the distributions of the breast cancer risk factors - menarche, first birth, menopause, and weight - in Hiroshima and Nagasaki, Japan. American Journal of Epidemiology 118 78-89.

Hofseth LJ, Raafat AM, Osuch JR, Pathak DR, Slomski CA \& Haslam SZ 1999 Hormone replacement therapy with estrogen or estrogen plus medroxyprogesterone acetate is associated with increased epithelial proliferation in the normal postmenopausal breast. Journal of Clinical Endocrinology and Metabolism 84 $4559-4565$.

Irwin KL, Rosero-Bixby L, Oberle MW, Lee NC, Whatley AS, Fortnery JA \& Bonhomme MG 1988 Oral contraceptives and cervical cancer risk in Costa Rica. Journal of the American Medical Association 259 59-64.

Japan Statistical Yearbook 1998 Table 2-25. Statistics Bureau of the Management and Coordination Agency, Government of Japan 1997.

Key TJA \& Pike MC 1988a The dose-effect relationship between 'unopposed' oestrogens and endometrial mitotic rate: its central role in explaining and predicting endometrial cancer risk. British Journal of Cancer 57 205-212.

Key TJA \& Pike MC 1988b The role of estrogens and progestogens in the epidemiology and prevention of breast cancer. European Journal of Cancer and Clinical Oncology 24 29-43.

Key TJA, Chen J, Wang DY, Pike MC \& Boreham J 1990 Sex hormones in women in rural China and in Britain. British Journal of Cancer 62 631-636.

King RJB \& Whitehead MI 1984 Progestin action in relation to the prevention of endometrial abnormalities. In Medical Management of Endometriosis, pp 67-77. Eds J-P Raynaud, T Ojasoo \& L Martini. New York: Raven Press.

Konishi I, Fujii S, Nonogaki H, Nanbu Y, Iwai T \& Mori T 1991 Immunohistochemical analysis of estrogen receptors, progesterone receptors, Ki-67 antigen, and human papillomavirus DNA in normal and neoplastic epithelium of the uterine cervix. Cancer 68 1340-1350.

Lane G, Siddle NC, Ryder TA, Pryse-Davies J, King RJB \& Whitehead MI 1986 Is Provera the ideal progesterone for addition to postmenopausal estrogen therapy? Fertility and Sterility 45 345-352.

Magnusson C, Baron JA, Correia N, Bergstrom R, Adami H-O \& Persson I 1999 Breast-cancer risk following long-term oestrogen- and oestrogen-progestin-replacement therapy. International Journal of Cancer 81 339-344.

Miles RA, Paulson RJ, Lobo RA, Press MF, Dahmoush L \& Sauer MV 1994 Pharmacokinetics and endometrial tissue levels of progesterone after administration by intramuscular and vaginal routes: a comparative study. Fertility and Sterility 62 485-490.

Narod SA, Risch H, Moslehi R, Dorum A, Neuhausen S, Olsson H, Provencher D, Radice P, Evans G, Bishop S, Brunet J-S \& Ponder BJ 1998 Oral contraceptives and the risk of hereditary ovarian cancer. New England Journal of Medicine 339 424-428.

Paterson MEL, Wade-Evans T, Sturdee DW, Thom MH \& Studd JWW 1980 Endometrial disease after treatment with oestrogens and progestogens in the climacteric. British Medical Journal 22 822-824.

Peters RK, Thomas D, Hagan DG, Mack TM \& Henderson BE 1986 Risk factors for invasive cervical cancer among Latinas and Non-Latinas in Los Angeles County. Journal of the National Cancer Institute 77 1063-1077.

Pike MC 1987 Age-related factors in cancers of the breast, ovary and endometrium. Journal of Chronic Diseases 40 59-69.

Pike MC \& Spicer DV 1993 Oral contraceptives and cancer. In Contraception, pp 67-84. Eds D Shoupe \& F Haseltine. New York: Springer-Verlag.

Pike MC, Ross RK, Lobo RA, Key TJA, Potts M \& Henderson BE 1989 LHRH agonists and the prevention of breast and ovarian cancer. British Journal of Cancer 60 142-148.

Pike MC, Spicer DV, Dahmoush L \& Press MF 1993 Estrogens, progestogens, normal breast cell proliferation, and breast cancer risk. Epidemiologic Reviews 15 17-35.

Pike MC, Peters RK, Cozen W, Probst-Hensch NM, Felix JC, Wan PC \& Mack TM 1997 Estrogen-progestin replacement therapy and endometrial cancer. Journal of the National Cancer Institute 89 1110-1116.

Rebbeck TR, Levin AM, Eisen A, Snyder C, Watson P, Cannon-Albright L, Isaacs C, Olopade O, Garber J, Godwin AK, Daly MB, Narod SA, Neuhausen SL, Lynch HT \& Weber BL 1999 Breast cancer risk after bilateral prophylactic 
oophorectomy in BRCA1 mutation carriers. Journal of the National Cancer Institute 91 1475-1479.

Risch HA, Weiss NS, Lyon JL, Daling JR \& Liff JM 1983 Events of reproductive life and the incidence of epithelial ovarian cancer. American Journal of Epidemiology 177 128-139.

Ross RK, Paganini-Hill A, Wan PC \& Pike MC 2000 Estrogen versus estrogen-progestin hormone replacement therapy: effect on breast cancer risk. Journal of the National Cancer Institute 92 328-332.

Schairer C, Lubin J, Troisi R, Sturgeon S, Brinton L \& Hoover R 2000 Menopausal estrogen and estrogen-progestin replacement therapy and breast cancer risk. Journal of the American Medical Association 283 485-491.

Schiff I, Sela HK, Cramer D, Tulchinskiy D \& Ryan KJ 1982 Endometrial hyperplasia in women on cyclic or continuous estrogen regimens. Fertility and Sterility 37 79-82.

Shoupe D, Meme D, Mezrow G \& Lobo RA 1991 Prevention of endometrial hyperplasia in postmenopausal women with intrauterine progesterone. New England Journal of Medicine 325 $1811-1812$

Spicer D, Shoupe D \& Pike MC 1991 GnRH agonists as contraceptive agents: predicted significantly reduced risk of breast cancer. Contraception 44 289-310.

Spicer DV, Pike MC, Pike A, Rude R, Shoupe D \& Richardson J 1993 Pilot trial of a gonadotropin hormone agonist with replacement hormones as a prototype contraceptive to prevent breast cancer. Contraception 47 427-444.

Spicer D, Ursin G, Parisky YR, Pearce JG, Shoupe D, Pike A \& Pike MC 1994 Changes in mammographic densities induced by a hormonal contraceptive designed to reduce breast cancer risk. Journal of the National Cancer Institute 86 431-436.

Waterhouse J, Muir C, Correa P \& Powell J (eds) 1976 Cancer Incidence in Five Continents, vol 3. Scientific Publication No. 15. Lyon: International Agency for Cancer Research.

Weiderpass E, Hans-Olov A, Baron JA, Magnusson C, Bergstrom R, Lindgren A, Correia N \& Persson I 1999 Risk of endometrial cancer following estrogen replacement with and without progestins. Journal of the National Cancer Institute 91 11311137.

Willett WC, Bain C, Hennekens CH, Rosner B \& Speizer FE 1981 Oral contraceptives and risk of ovarian cancer. Cancer 48 16841687.

Williams G, Anderson E, Howell A, Watson R, Coyne J, Roberts SA \& Potten CS 1991 Oral contraceptive (OCP) use increases proliferation and decreases oestrogen receptor content of epithelial cells in the normal human breast. International Journal of Cancer 48 206-210.

Williams DB, Voigt BJ, Fu YS, Schoenfeld MJ \& Judd HL 1994 Assessment of less than monthly progestin therapy in postmenopausal women given estrogen replacement. Obstetrics and Gynecology 84 787-793. 
